Research letter

\title{
Antecubital vein access for balloon pulmonary angioplasty in patients with chronic thromboembolic pulmonary hypertension: safe new approach
}

\author{
Nikolay M. Danilov, Yuriy G. Matchin, Olesya V. Sagaydak, Madina B. Karabasheva, Tatyana V. Balakhonova, \\ Irina E. Chazova
}

National Medical Research Center of Cardiology, Moscow, Russia

Received 15 January 2019, Revised 31 January 2019, Accepted 7 February 2019

(C) 2019, Danilov N.M., Matchin Yu.G., Sagaydak O.V., Karabasheva M.B., Balakhonova T.V., Chazova I.E.

(C) 2019, Russian Open Medical Journal

Abstract: Background - Balloon pulmonary angioplasty (BPA) is an effective and safe method of treating patients with inoperable chronic thromboembolic pulmonary hypertension (CTEPH). Currently, femoral and jugular vein accesses are the most frequently used for BPA. Authors all over the world report different numbers of access side complications, mostly exceeding $0.4 \%$. We suggest new alternative access for BPA procedures - antecubital vein access (AVA) that is safe and easy.

Methods - In 2015-2017 period we performed 64 BPA in 19 patients with inoperable CTEPH. We performed BPA via AVA using standard radial access kit and in case of unsuccessful AVA we switched to femoral vein access (FVA). All procedures were successful with no serious complications and patients demonstrated clinical and hemodynamic improvement.

Results - Fifty-six from 64 procedures (87.5\%) were performed via AVA, 8 - via femoral access (12.5\%). There were no severe complications via AVA, local extravasates were managed with bandage compression.

Conclusion - Performing BPA via AVA in patients with CTEPH is a new alternative approach that is safe and easy.

Keywords: balloon pulmonary angioplasty, chronic thromboembolic pulmonary hypertension, antecubital vein access, pulmonary hypertension.

Cite as Danilov NM, Matchin YuG, Sagaydak OV, Karabasheva MB, Balakhonova TV, Chazova IE. Antecubital vein access for balloon pulmonary angioplasty in patients with chronic thromboembolic pulmonary hypertension: safe new approach. Russian Open Medical Journal $2019 ; 8$ : e0107.

Correspondence to Olesya V. Sagaydak. Address: Hypertension Department, National Medical Research Center for Cardiology, 3d Cherepkovskaya str., Moscow, 121552, Russia. Tel: +7 903 6871239. E-mail: olesyasagaydak@gmail.com.

\section{Introduction}

Pulmonary thromboembolic disease is a severe pathology with high mortality and invalidization rate. Patients who survived are still at great risk of cardiovascular events and up to $4 \%$ develop chronic thromboembolic pulmonary hypertension (CTEPH) [1].

CTEPH is characterized by progressive rising of pulmonary vascular resistance (PVR) and right ventricular heart failure [2-4]. Recently treatment of these patients was limited to drug therapy and thrombendarterectomy $[2,5,6]$. The last one being very effective and bringing pulmonary pressure down to normal values has unfortunately indication limits. Patients with high PVR, distal lesions and co-morbidities are at high operation risk and specialists have to refuse thrombendarterectomy and stick to conservative treatment.

In 2001 Feinstein et al proposed and described a new approach for invasive treatment of inoperable CTEPH patients balloon angioplasty of pulmonary arteries, but because of the large numbers of life-threatening complications, the method was not adopted and then only in 2012 group of physicians from Japan [7-9] revived this method again with modifications. In short time balloon pulmonary angioplasty (BPA) demonstrated its high efficiency, it was approved by medical society all over the world and took its place in treatment algorithm for inoperable patients with CTEPH.

Routine access for BPA used by specialists all over the world was via femoral and jugular veins. Though treatment itself has proven its safety, still there are incidents of puncture side complications: pseudoaneurysms, arteriovenous fistulas, retroperitoneal hematomas, carotid artery puncture, etc. - all these events are at high risk of initiating progressive worsening of patient status. Marius M. Hoeper et al. [10] in their study of more than 6,000 right heart catheterization procedures reported $0.4 \%$ rate of puncture complications (antecubital vein access (AVA) was not used).

In expert pulmonary hypertension center based on National Medical Research Center of Cardiology in Moscow (Russia) since the end of 2014 we have been performing BPA, approximately 4-5 procedures per week. One patient have to bypass from 4 to 8 sessions (mean 4.6 \pm 1.9 ). In order to add comfort and safety to the procedure in January of 2015 we suggested and started to perform BPA via AVA.

Aim of the study: to evaluate safety of AVA during BPA for patients with $\mathrm{CTEPH}$. 
Table 1. Characteristics of AVA

\begin{tabular}{|c|c|}
\hline Parameters & Value \\
\hline Successful procedures via AVA, no. (\%) & $56(86.5 \%)$ \\
\hline Failed procedures via AVA, no. (\%) & $8(12.5 \%)$ \\
\hline Procedures per one antecubital vein (reusability), $M \pm S D$ & $26 \pm 16$ \\
\hline $\begin{array}{l}\text { Maximal amount of procedures per antecubital vein, no. } \\
\text { Mean diameter of veins, } \mathrm{mm}, \mathrm{M} \pm \mathrm{SD} \text { : }\end{array}$ & 6 \\
\hline - Antecubital veins & $3.5 \pm 0.9$ \\
\hline - Basilica veins & $4.1 \pm 1.5$ \\
\hline \multicolumn{2}{|l|}{ Main reasons for AVA failure, no.: } \\
\hline - Diameter of the vein $<2 \mathrm{~mm}$ & 3 \\
\hline - Difficulties in placement of Braunul micro-catheter & 1 \\
\hline - Vascular abnormalities & 3 \\
\hline - Vein perforation with extravasation & 1 \\
\hline
\end{tabular}

Quantitative data presented as mean with standard deviation - $\mathrm{M} \pm \mathrm{SD}$; qualitative data presented as frequency and percentage - no. (\%).

\begin{tabular}{lcc}
\multicolumn{1}{c}{ Table 2. Efficiency of 64 BPA } & & \\
\hline \multicolumn{1}{c}{ Parameter } & Before BPA & After all sessions \\
\hline Clinical characteristic & & \\
FC & $2.5 \pm 0.8$ & $1.3 \pm 0.4$ \\
$6 \mathrm{MWT}$ distance, $\mathrm{m}$ & $400 \pm 105$ & $523 \pm 85$ \\
\hline Hemodynamic parameters & & \\
$\mathrm{mPAP}, \mathrm{mmHg}$ & $49 \pm 13$ & $35 \pm 18$ \\
$\mathrm{Cl}, \mathrm{L} / \mathrm{min} / \mathrm{m}^{2}$ & $2.2 \pm 0.6$ & $4.3 \pm 1.5$ \\
$\mathrm{PVR}, \mathrm{WU}$ & $11.0 \pm 4.7$ & $7.2 \pm 4.7$
\end{tabular}

Data presented as mean with standard deviation - M $\pm \mathrm{SD}$.

FC, functional class; 6MWT, 6-minute walking test; mPAP, mean pulmonary artery pressure; $\mathrm{Cl}$, cardiac index; PVR, pulmonary vascular resistance; BPA, balloon pulmonary angioplasty.
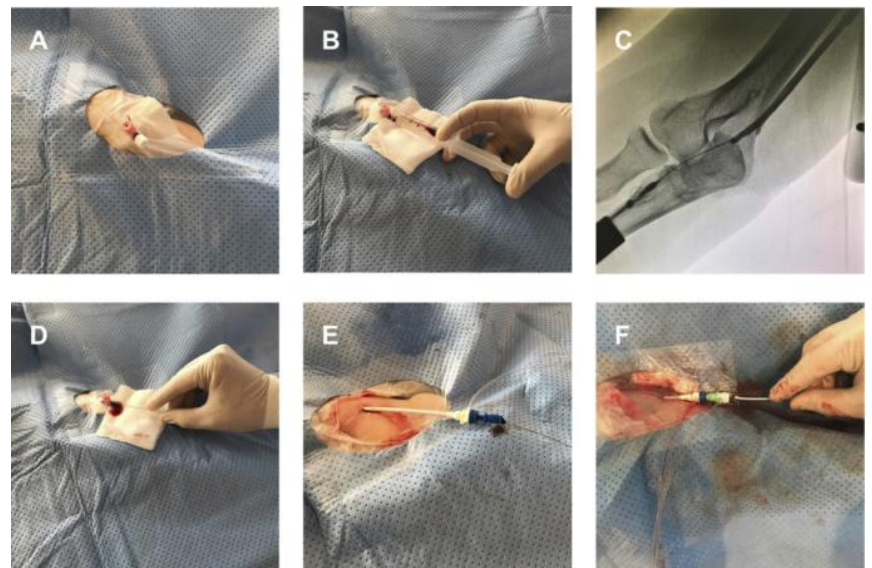

Figure 1. A - Peripheral intravenous catheter inserted into the antecubital vein in the medial direction. $B$ and $C-$ Control angiography to make sure the right direction towards $v$. basilica. D - Insertion of wire into the peripheral catheter. $\mathrm{E}$ - Insertion of $8 \mathrm{~F}$ introducer. $\mathrm{F}-$ Insertion of $6 \mathrm{~F}$ long sheath and $6 \mathrm{~F}$ guiding catheter.

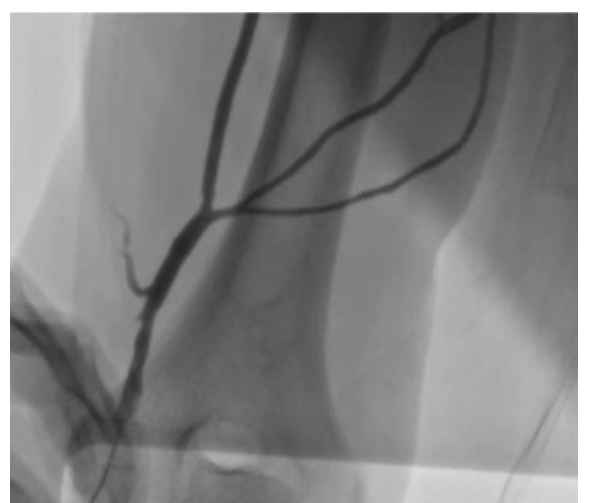

Figure 2. Vascular abnormalities of $v$. basilica.

\section{Material and Methods}

Our study was aproved by the ethics committees. All patients signed informed consent.

From January 2015 till June 2017 we performed 64 BPA via AVA in 19 patients (11 women) with inoperable CTEPH (before that only femoral vein access (FVA) and jugular vein access was used). All included patients were white race with average age $43 \pm 13$ years, average weight $77.0 \pm 17,5 \mathrm{~kg}$ and hight $170.0 \pm 9,7 \mathrm{~cm}$. The indications for BPA were determined by multidisciplinary team which included cardiologist, cardiac surgeon, interventional specialist and computed tomography (CT) specialist. Clinical features of the group as follows: functional class (FC) $-2.5 \pm 0.8$, 6minute walking test $(6 \mathrm{MWT})$ distance $-400 \pm 105 \mathrm{~m}$. Hemodynamic parameters: mean pulmonary artery pressure (mPAP) $-49 \pm 13$ $\mathrm{mmHg}$, cardiac index $(\mathrm{Cl})-2.2 \pm 0.6 \mathrm{~L} / \mathrm{min} / \mathrm{m}^{2}, \mathrm{PVR}-11.0 \pm 4.7 \mathrm{WU}$.

To evaluate the diameter of the vein and its status after previous BPA sessions ultrasound study was performed.

The algorithm of performing BPA was as described by its founders from Japan [7] with only access site modification (antecubital vein access). In case of unsuccessful AVA we switched to FVA.

Usually for AVA basilica vein was used as the widest and the most available one. There is no need in any special equipment standard radial access kit is used. Standard peripheral intravenous catheter $1.1 \times 32 \mathrm{~mm}$ is placed in the antecubital vein in the medial direction to insert the wire into the $v$. basilica (Figure 1). Before inserting the wire we perform angiography of basilica vein. Using the radial wire the $8 \mathrm{~F} 11 \mathrm{~cm}$ introducer is inserted. Changing radial wire for the Amplatz $260 \mathrm{~cm} 0.035$ inch wire we insert $6 \mathrm{~F} 90$ $\mathrm{cm}$ long sheath that riches the pulmonary artery. Through the long sheath we insert 6 F $125 \mathrm{~cm}$ guiding Judkins Right 4 (JR4) or Multipurpose-A (MPA) catheter. Placing the cubital peripheral intravenous catheter is everyday practice in cardiology centers and can be performed with access team during the preparation step out of Cathlab. This shortens the time of the procedure and allows the physician to start the BPA right away.

\section{Results}

All 64 procedures were successful with no serious complications. Fifty-six from 64 procedures (87.5\%) were successfully performed via AVA. Mean diameter of antecubital and basilica veins measured by ultrasound were $3.5 \pm 0.9 \mathrm{~mm}$ and $4.1 \pm 1.5 \mathrm{~mm}$. In 8 cases (12.5\%) we failed to perform AVA due to the following reasons: diameter of the vein was less than $2 \mathrm{~mm}$ $(n=3)$, difficulties in placement of Braunul micro-catheter $(n=1)$, vascular abnormalities $(n=3)$ (Figure 2 ), vein perforation with extravasation $(n=1)$. Local extravasates were treated with bandage compression. There were no other complications via AVA. These procedures $(n=8)$ were succefully performed via femoral vein access. Maximum amount of procedures performed through the same antecubital vein was 6 . In average, there were $2.6 \pm 1.6$ procedures per one antecubital vein in all 19 patients (Table 1 ).

All 64 BPA were effective and patients demonstrated clinical and hemodynamic improvement. We would also like to draw attention to the fact that choice of approach didn't influence the effect of BPA. The results of all procedures are in Table 2. 


\section{Discussion}

Performing BPA via AVA demonstrated its safety and versatility. When working through femoral or jugular vein access we have to keep in mind that founders of the method recommend using right jugular vein for right lung manipulations and femoral vein for the left lung manipulations, which sometimes can be quite tricky. Antecubital access is vice versa suitable for procedures on both lungs. What is more, while performing BPA via AVA only two operators are needed as there is no necessity in stabilizing the long sheath with the third physician. Antecubital access is as comfortable for patient as it is for interventionist: AVA decreases the duration of the procedure and provides early mobilization of the patient with bed rest exclusion.

Despite thin vein walls and small diameter, we also have shown the suitability for repeat access thought the same antecubital vein during all BPA sessions. That was proven by ultrasound control before every session. Sometimes when v.basilica is too small it is possible to make an access through v.cephalica, but this could be quite challenging because of anatomical features and angle in cephalica-axillarry "T-junction".

Antecubital vein access is versatile, but it has some limitations. The most common is a spasm of the vessel that usually doesn't disturb the procedure, but in some cases, it can be a reason for switching to another access. To overcome spasm of the vessel vein vasodilators (i.e. nitrates) can be used. Calcium channel blockers are not recommended as these can provoke pulmonary edema. The other limitation is a rare anomaly - left sided superior vena cava, that blocks the way to the right heart. In this case, the only way to perform the right heart catheterization is FVA.

\section{Conclusion}

Performing BPA via AVA in patients with CTEPH is a new safe alternative approach that makes the procedure comfortable for patient. AVA decreases the duration of the procedure and provides early mobilization of the patient with bed rest exclusion.

Antecubital puncture side complications are occasional and mild. New alternative access is suitable for BPA on both lungs and can be reused during series of BPA sessions in one patient.

We suggest using AVA in all suitable BPA sessions.

Conflict of interest: none declared.

\section{Funding}

The authors have reported that no funding was received for this study.

\section{References}

1. Pengo V, Lensing AW, Prins $\mathrm{MH}$, Marchiori A, Davidson BL, Tiozzo F, et al. Incidence of chronic thromboembolic pulmonary hypertension after pulmonary embolism. N Engl J Med 2004; 350: 2257-2264. https://dx.doi.org/10.1056/NEJMoa032274.

2. Piazza G, Goldhaber SZ. Chronic thromboembolic pulmonary hypertension. N Engl J Med 2011; 364: 351-360. https://dx.doi.org/10.1056/NEJMra0910203.

3. Fedullo $\mathrm{P}$, Kerr KM, Kim NH, Auger WR. Chronic thromboembolic pulmonary hypertension. Am J Respir Crit Care Med 2011; 183: 16051613. https://dx.doi.org/10.1164/rccm.201011-1854CI.

4. Humbert M. Pulmonary arterial hypertension and chronic thromboembolic pulmonary hypertension: pathophysiology. Eur Respir Rev 2010; 19: 59-63. https://dx.doi.org/10.1183/09059180.00007309.
5. Pepke-Zaba J, Delcroix M, Lang I, Mayer E, Jansa P, Ambroz D, et al. Chronic thromboembolic pulmonary hypertension (CTEPH): results from an international prospective registry. Circulation 2011; 124: 1973-1981. https://dx.doi.org/10.1161/CIRCULATIONAHA.110.015008.

6. Mayer E, Jenkins D, Lindner J, D’Armini A, Kloek J, Meyns B, et al. Surgical management and outcome of patients with chronic thromboembolic pulmonary hypertension: results from an international prospective registry. J Thorac Cardiovasc Surg 2011; 141: 702-710. https://dx.doi.org/10.1016/i.jtcvs.2010.11.024.

7. Mizoguchi $\mathrm{H}$, Ogawa A, Munemasa $\mathrm{M}$, Mikouchi $\mathrm{H}$, Ito $\mathrm{H}$, Matsubara $\mathrm{H}$. Refined balloon pulmonary angioplasty for inoperable patients with chronic thromboembolic pulmonary hypertension. Circ Cardiovasc Interv 2012; 5 : 748-755. https://dx.doi.org/10.1161/CIRCINTERVENTIONS.112.971077.

8. Sugimura K, Fukumoto $Y$, Satoh K, Nochioka K, Miura Y, Aoki T, et al. Percutaneous transluminal pulmonary angioplasty markedly improves pulmonary hemodynamics and long-term prognosis in patients with chronic thromboembolic pulmonary hypertension. Circ J 2012; 76: 485-488. https://doi.org/10.1253/circj.CJ-11-1217.

9. Kataoka M, Inami T, Hayashida K, Shimura N, Ishiguro H, Abe T, et al. Percutaneous transluminal pulmonary angioplasty for the treatment of chronic thromboembolic pulmonary hypertension. Circ Cardiovasc Interv 2012; $\quad$ 5: 756-762 https://dx.doi.org/10.1161/CIRCINTERVENTIONS.112.971390.

10. Hoeper MM, Lee SH, Voswinckel R, Palazzini M, Jais $X$, Marinelli $A$, et al. Complications of right heart catheterization procedures in patients with pulmonary hypertension in experienced centers. J Am Coll Cardiol 2006; 48(12): 2546-2552. https://doi.org/10.1016/i.jacc.2006.07.061.

\section{Authors:}

Nikolay M. Danilov - MD, DSc, Leading Researcher, Hypertension Department, National Medical Research Center of Cardiology, Moscow, Russia. https://orcid.org/0000-0001-9853-9087.

Yuriy G. Matchin - MD, DSc, Chief of the Department of Endovascula Treatment, National Medical Research Center of Cardiology, Moscow, Russia. https://orcid.org/0000-0002-0200-852X

Olesya V. Sagaydak - MD, PhD, Researcher, Hypertension Department, National Medical Research Center of Cardiology, Moscow, Russia. https://orcid.org/0000-0002-2534-8463.

Madina B. Karabasheva - MD, Graduate Student, Hypertension Department, National Medical Research Center of Cardiology, Moscow, Russia. http://orcid.org/0000-0001-6734-4324.

Tatyana V. Balakhonova - MD, DSc, Chief of the Department of Vascular Ultrasound Diagnostics, National Medical Research Center of Cardiology, Moscow, Russia. https://orcid.org/0000-0002-7273-6979.

Irina E. Chazova - MD, DSc, Professor, Academician of Russian Academy of Science, Chief of the Hypertension Department, National Medical Research Center of Cardiology, Moscow, Russia. https://orcid.org/0000-0002-9822$\underline{4357 .}$. 